\title{
Thermal insulation: operational properties and methods of research
}

\author{
Alexey Zhukov ${ }^{*}$, Tatiana Konoval'tseva ${ }^{2}$, Ekaterina Bobrova $^{3}$, Ekaterina Zinovieva ${ }^{1}$, \\ Kazbek Ivanov ${ }^{1}$ \\ ${ }^{1}$ Moscow State University of Civil Engineering, Yaroslavskoe shosse, 26, Moscow, 129337, Russia \\ ${ }^{2}$ ROCKWOOL, 9 Zemlyanoy Val St., Moscow, 105064, Russia \\ ${ }^{3}$ High School of Economics., 20 Myasnitskaya St, Moscow, 10100, Russia
}

\begin{abstract}
Construction system consists of materials with different properties. The use of materials in the design should ensure maximum of its performance and its durability. The use of thermal insulation materials is an effective way to form the thermal envelope of a building, reducing energy costs and increasing the durability of building structures. The properties of materials are determined by their structure, which is formed in the process of technological influences. Formation of the insulating shell of oil and gas industry objects is possible only when considering the special features of the thermal insulation layer in the construction and the use of high-quality materials that retain their characteristics, both in the early stages of operation and throughout the calculation period. The first is achieved by competent design, the second - the possibility of assessing the properties of thermal insulation (and predicting changes in these properties over time) directly in the construction site.The methodology for assessing the properties of insulating products includes two main components: testing facility and methodology for assessing operational stability. The methodology of conducting accelerated tests and prediction of durability is tested for mineral wool products of a layered, corrugated and volumeoriented structure. The test results give good convergence with the methods recommended by the building codes.
\end{abstract}

\section{Introduction}

Construction system including the insulation system involves the use of construction materials different purposes to form at optimum cost structure with desired properties for the application. As a criterion for the effectiveness of the system can be considered a criterion its energy (environmental) parameters, based on an assessment of four groups of factors. The first is the energy intensity of the materials of the insulation system when they are manufactured. The second is the energy intensity of the assembly of the structure. The third one is the economic effect from the operation of the system, which considers both energy saving, both the period of unattended operation of the system and its fire safety. The fourth factor is the comfort of the environment for a person: from the point of view of the

\footnotetext{
*Corresponding author: 1j211@yandex.ru
} 
temperature and humidity conditions, as well as the acoustic characteristics of this environment (first of all, protection against noise and vibrations).

Often constructions are made of materials that are easy to contribute to the emergence and development of fire hazards. The use of insulating materials on non-combustible mineral fibers in specialized areas should be centralized and complex. This specialized field of application includes marine structures, oil and gas platforms and infrastructure facilities.

The fire resistance limit of a building structure is set by the time in minutes from the beginning of the thermal effect on the structure before one or several successive states occur: in terms of carrying capacity (R), in integrity (E), in thermal conductivity of convective (I) and in thermal conductivity by radiation (W). Limit is the condition of the structure, in which it loses the ability to retain the bearing and (or) guarding functions in a fire.

Insulating systems used for oil and gas industry facilities must meet the requirements of both fire safety and operational and corrosion resistance. It should also be considered that because of ignition, it is possible to ignite hydrocarbons, which seriously changes the conditions of the fire. The temperature in the fire zone can reach $900{ }^{\circ} \mathrm{C}$ and more, and the fire action itself can be accompanied by the release of chemically active substances $[5,6]$.

Increased fire resistance (up to refractoriness) has a group of fibers: mullite-siliceous, kaolinic, basaltic. The production of these fibers is associated with significant energy costs and is technologically challenging.

Energetically acceptable option is that within the existing (classic) technology for producing a fiber from rocks (modified cupola oxy, heated tray, a four-roll centrifuge and tilt camera forming a primary mineral wool mat) demonstrated the possibility of obtaining the fiber with temperature resistance up to $1100{ }^{\circ} \mathrm{C}$. The study examined the possibility of using insulating products (in particular double-density) of stone wool. The main emphasis is to assess the operational stability of these products [7-9].

\section{Experimental}

The main factors of aggressive influence are the presence of moisture in the thermal insulating layer with dissolved mineral substances, the temperature factor (elevated and negative temperatures, $0{ }^{\circ} \mathrm{C}$ transition), migration in the heat-insulating layer of the steamair mixture, direct mechanical and vibrational effects. All these influences lead to an inevitable decrease in the quality of the insulation, and an estimate of the intensity of this reduction is the subject of the developed methods [10-12].

The standard and recommended documents, the procedures of HSE GASIS, NIISF RAACS, ROCKWOOL, NRU MGSU is measured the evaluation operational stability of thermal insulation by its artificial aging. The traditional criterion in the current methods is water resistance. According to the current GOST 9573 and GOST 17177, it is evaluated by the degree of reduction in strength and compressibility after keeping the samples of mineral wool slabs for 3 days in a desiccator at a temperature $22 \pm 5{ }^{\circ} \mathrm{C}$ and humidity $98 \pm 2 \%$. CNIIPromzdany and GASIS with the participation of MGSU and LLC "Maxmir" under the guidance of prof. Yu. L. Bobrov developed cameras and techniques that made it possible to conduct operative studies of the moisture resistance of mineral wool products of various densities, both in factory and in building conditions for 20-25 min [13, 14].

General view of the cameras for making express tests is shown in Fig. 1. The chamber in Fig. 1a is designed to determine the moisture resistance of rigid slabs by changing the compressive strength at $10 \%$ deformation after they have been aged over boiling water. The camera in Fig. 1b is designed to determine the moisture resistance of soft and semi-rigid slabs by changing their compressibility after exposure to boiling water. 

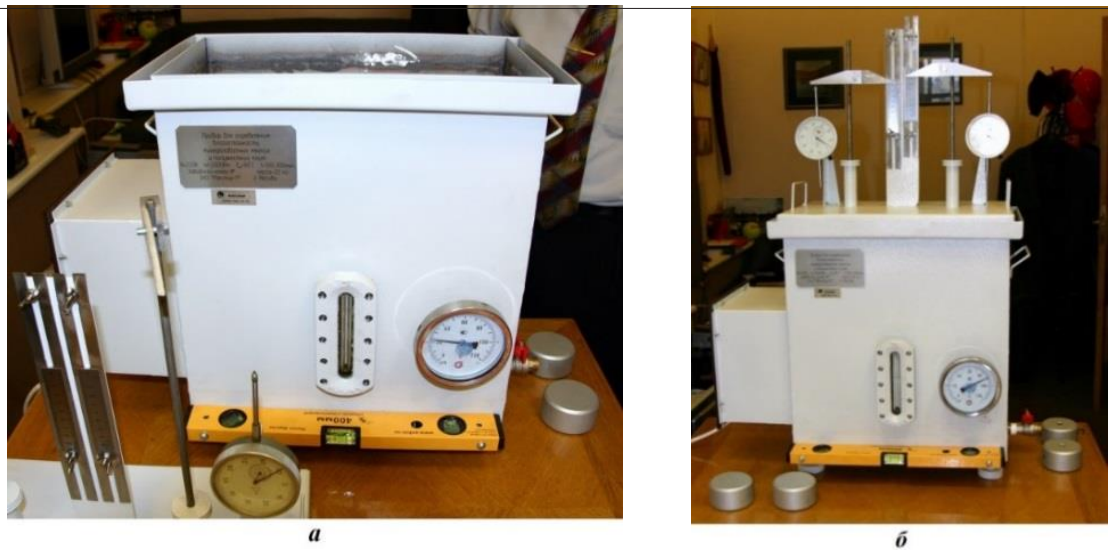

Fig. 1. Cameras for express tests: $a$ - camera for soft slabs tests; $b$ - camera for soft slabs tests

Application of this method not only significantly accelerated the evaluation of water resistance of various mineral wool thermal insulation materials (MTM), but also allowed to accumulate data for a possible practical improvement method and design of the chamber for determining the moisture resistance of MTM with horizontal and vertical orientation of the fibers in their structure. The obtained data showed that values between strength reduction slabs with their exposure over boiling water and stored in a desiccator in humid air at 18-20 ${ }^{\circ} \mathrm{C}$ there is a directly proportional relationship. A deeper study of this question splatehowed that significantly affected by the type and degree of cure of the binder in the finished slabs.

Simultaneously with the decrease in strength were noted the signs of structuring of the uncured part of the binder during longer tests and irreversible deformation of samples of low density $\left(35-70 \mathrm{~kg} / \mathrm{m}^{3}\right)$ when removed from the chamber after completion of the test and in the fastening clamps rupture device.

This method evaluates the moisture resistance of the insulation specimen from the change in compressibility. For most mineral wool products on synthetic binders, the relative change in compressibility is $5-20 \%$. A significant excess of these values may indicate a deterioration in the quality of the binder, violations of production technology, storage regimes, etc.

\section{Results}

Studies of the operational properties of mineral wool products have shown that their properties change during climatic tests, and the nature of these changes is different. It has been established that the strength characteristics of mineral wool slabs decrease with time. These changes are both rigid slabs (density $160-220 \mathrm{~kg} / \mathrm{m}^{3}$ ) - decrease of compression strength at $10 \%$ strain, and low density slabs - increase compressibility. For rigid slabs the greatest changes occur within the first 3-5 years of use of the material in the coating and in the first 100-150 test cycles in climatic chambers.

Prediction of the operational stability of rigid mineral wool slabs allows for more accurate results using the analytical method. In accordance with this method, the probable law of decreasing strength (the operational stability curve) is first experimentally established, then the constants of the calculation formulas are determined.

Character reducing the initial strength of mineral wool slabs in their operation in coatings of industrial buildings with membrane roofs can be described by a differential equation of the form: 


$$
\frac{d \sigma_{(n)}}{d n}+\alpha \sigma(n)=\alpha \sigma^{*}(1)
$$

$\sigma_{(n)}$ - the current value of the compressive strength at $10 \%$ deformation; $\sigma^{*}$ - compressive strength slabs in the stage of practical failure (failure) in the coating under the roll roofing; $\alpha$ - figure characterizing complex operational factors influence the reduction in time of physico-chemical and thermal protective properties of mineral wool; $n$ - the predicted duration of operation of the mineral wool insulation.

$$
\begin{gathered}
\left(\sigma_{(n)}\right)_{n=0}=\sigma_{0}(2) \\
\sigma_{(n)}=\left(\sigma_{0}-\sigma^{*}\right) e^{-\alpha n}+\sigma^{*}(3)
\end{gathered}
$$

$\sigma_{0}-$ the strength of the slabs before sticking a roll of carpet on them.

Under the predicted operational durability, consequently, is meant the estimated time during which the layer of insulation from mineral wool materials can provide the designed heat-shielding qualities of the enclosing structure. When insufficient strength of the heat insulation layer it is possible deformation, which leads to lower projected thermal resistance with all the negative consequences.

In experiments we studied the properties of mineral wool products volume-oriented structure and an outer layer with power. The main factors determining their properties are the resistance of the binder and the characteristics (acidity modulus, diameter) of the fibers.

The criterion of the comparative resistance of the binder $(\mathrm{Kc})$, takes into account the influence of the type, quality and degree of curing of the synthetic binder (using which mineral wool slabs are made) on changing the properties of the binder in time in the product structure (Fig. 2).

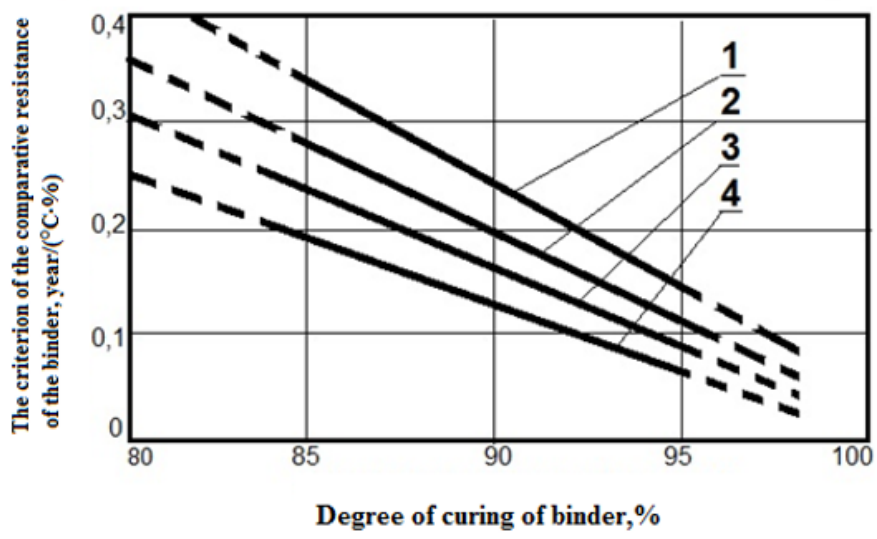

Fig. 2. Dependence the criterion of comparative resistance of synthetic binders (year $/{ }^{\circ} \mathrm{C} \cdot \%$ )) on the degree of their curing in a mineral wool slab: 1 - phenol grade B; 2 - neutralized phenol grade B; 3 phenol grade D and resins type SF-3047 H; 4 - resin SF-3047 N with AGM-9 modifier

Investigation of the durability of mineral wool products, including double density slabs, has shown that these products have significant reserves of durability.

Table 1. Physical and mechanical properties of slabs with reinforced outer layer

\begin{tabular}{|l|l|l|l|}
\hline Index & Qualitypassportdata & Test results & Normalized rate \\
\hline Delaminationstraight, $\mathrm{kPa}$ & 9,3 & 5,9 & not less than 4,0 \\
\hline
\end{tabular}




\begin{tabular}{|l|l|l|l|}
\hline Organic matter content, $\%$ & 3,4 & 3,4 & not more than 4,0 \\
\hline $\begin{array}{l}\text { Thermal conductivity at } 10 \\
{ }^{\circ} \mathrm{C}, \mathrm{W} /(\mathrm{м} \cdot \mathrm{K})\end{array}$ & 0,033 & 0,035 & not more than 0,035 \\
\hline
\end{tabular}

Additional information about operational resistance of products can show the study of the slab's properties that are in harsh operating conditions. It happens that on the building sites mounted slabs can be in the open for a long time. This can happen for various reasons (lack of financing, interruptions in the supply of facing slabs, etc.). The conditions in which slabs are exposed are extreme (rain, snow, wind, exposure to sunlight). In this case, products can retain their quality passport for one to three seasons.

\section{Discussion}

The production of double density products is based on the technology of stone wool products using a charge with the acidity module $\mathrm{Mk}=1.8-2.2$. Melting of charge is carried out in modernized cupola furnaces. Processing of the melt into the fiber is carried out by a centrifugal-roll method with blowing of the fiber into the void-settling chamber.

Further, a basic carpet with a volume-oriented structure is formed, the carpet is heat treated and is formatted into products.

The technology of double density $s$ entered the practice of domestic production relatively recently and it can be said that it fully justified itself. The formation of double density is carried out with the help of a special complex (Fig. 3) and by sub-pressing the mineral wool carpet in a special way. Before the heat treatment chamber and in the chamber, there are used nip rolls and plate conveyors, the planes of which create an increased compressive force, which allows pressing the upper hardened layer of mineral wool to the lower one, and form a slab with high mechanical properties without introducing an additional binder.

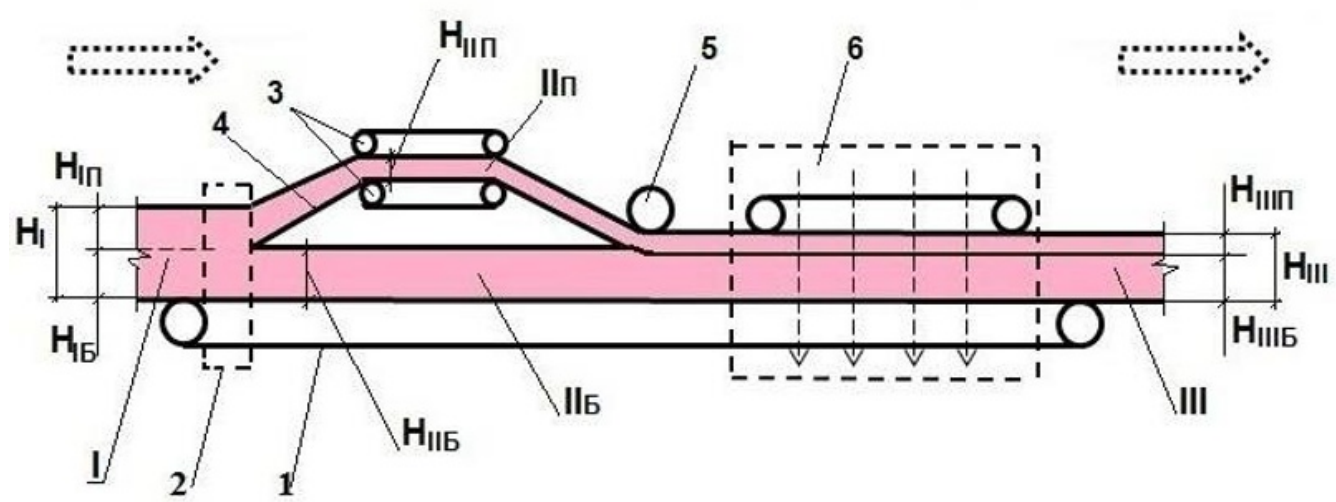

Fig.3. The scheme of formation the dual density mineral wool slabs. I - mineral wool carpet after dispensing equipment and presser; ІІП - upper layer (in the process of prepressing); ІІБ - lighter lower layer after cutting; III - mineral wool with polycondensed binder after the thermal treatment chamber. 1 - mesh conveyor, 2 - cutting apparatus 3 - sealing conveyors, 4 - directional table, 5 presser apparatus, 6 - thermal treatment chamber.

The thermal treatment of the mineral wool carpet is carried out by the heat carrier fluid (air heated to $200-240^{\circ} \mathrm{C}$ ) carpet layer. At the same time evaporation of moisture from the carpet (drying) and curing of the binder. The purpose of heat treatment is to stabilize the 
structure of the carpet by curing the binder, which occurs as a result of polycondensation. It is obvious that the replacement of the mesh conveyor to the plate and change the density of the mineral wool mat has the aerodynamics of a heat treatment a considerable influence. This should be considered when designing structures and modes of operation of the camera.

The carried out studies of the change in the strength characteristics (Fig. 4) of mineral wool products (strength at 10\% deformation or compressibility), their density and thermal conductivity made it possible to formulate the following conclusions.

First, the modern level of stone wool technology makes it possible to produce mineral fibers with an acidity module of $2-2.2$, which makes the fiber practically stable to the temperature-humidity, chemical and mechanical influences typical for the operation processes. Secondly, the volume-oriented mineral wool structure makes it stable to low compressive forces.

Thirdly, the irreversible deformation of samples during loading, as well as an increase in their density and thermal conductivity in the operation occurs as a result of weakening (or destruction) of the structure in the field of contacts of the fibers, where the fixing them omonolichennym binder. The main reason: incomplete homogenization of the binder and as a consequence - weakening of bonds in the areas of fiber contact. Elimination of this deficiency is a complex task, the basis of which is to study the processes of heat and mass transfer in the mineral fiber layer and, therefore, correction of the heat treatment regimens of the mineral wool carpet in conveyor chambers.

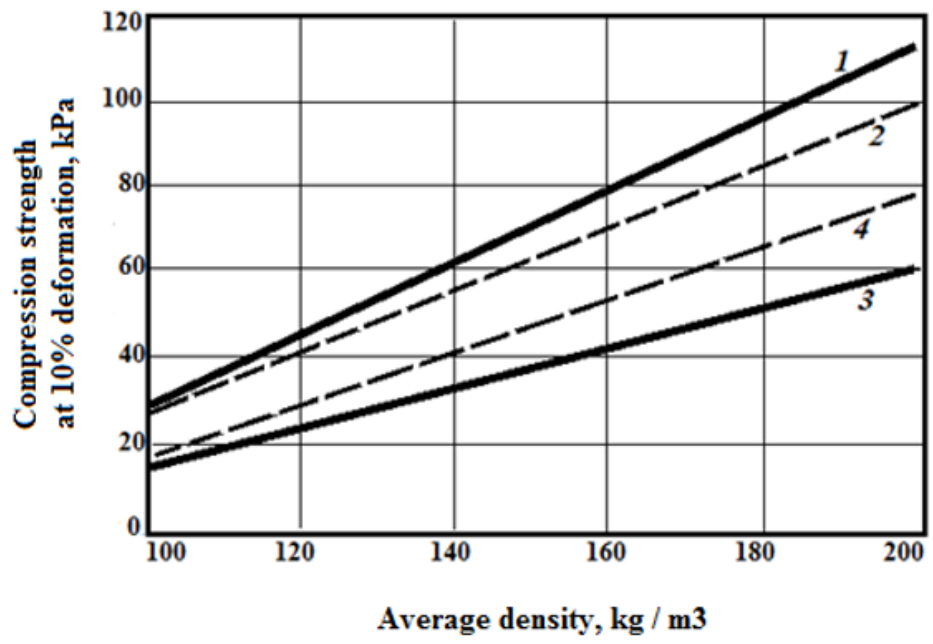

Fig. 4. Comparison of the compressive strength at $10 \%$ deformation from the average density of the thermal insulation layer for single-layer $(1,3)$ and double-density slabs $(2,4)$ slabs: 1,2 - slabs at the beginning of operation; 3, 4 - slabs after 10 years of operation

\section{Conclusions}

Operating resistance thermal insulating material is determined by its ability to withstand the temperature and humidity, mechanical stress, exposure to chemically active liquids and vapor without significant changes in functional properties and, especially the density and thermal conductivity. During the operation, the slabs are exposed to various influences, which in one way or another disturb the structure of the material, change the properties of 
the mineral fiber and the strength of the areas of contact. All these factors can be considered as reasons for the decrease in operational stability.

Installation of heat-insulating and sound-insulating materials on the basis of increased fire resistance fibers can be produced in various ways. Each company that specializes in this area, has its own rules and regulations for the installation of insulation materials. When installing insulation for fire retardant structures, it is necessary to adhere to the official drawings, according to which fire tests were conducted.

Systems of external wall structures of oil and gas platforms must meet the requirements and safety standards. External cladding should maintain its properties in conditions of sea climate and in conditions of low temperatures; protect structural elements from negative atmospheric influences. The frame of enclosing structures (walls) should have low thermal conductivity, while components for isolating aggregates generating vibrations and minimizing the transmission of vibrations and sound to structural elements of structures must be provided. Thermal insulation layers should provide normative thermal resistance of external walls, be non-combustible and do not contain components representing ecological hazard. Internal lining must also provide the necessary protection against fire impact, be made of waterproof materials and fully meet the requirements of interior decoration.

\section{References}

1. Bessonov I.V., Starostin A.V., Oskina V.M. (2011) About dimensionally stable fibrous insulation // Journal Herald MSUCE. 3. 2011. pp.134-139

2. Livchak V.I. (2002) A realistic approach to energy efficiency in the existing housing stock of the city // Magazine Energy Saving.2 002. 5. pp. 14-18

3. Zhuk P.M., Zhukov A.D. (2018). Normative legal base of environmental assessment of building materials: prospects for improvement // Ecology and industry of Russia. 2018. 4. pp. 52-57.

4. Arquis E., Cicasu C. (2006) Convection phenomen in mineral wool in-stalled on vertical walls // Proceedings of the International scientific-practical conference "Effective heat and sound insulating materials in modern construction and housing and communal services." Publishing house MSUCE, M., 2006 г. P. 18-21

5. Shmelev S.E. (2013). Ways to choose the optimal set of energy-saving measures. Building Materials, no.3, pp. 7-9.

6. Gnip I., Vaitkus S., Kersulis V., Vejelis S. (2012) Long-term prediction of creep strains of mineral wool slabs under constant compressive stress. Mech Time Depend Mater. 2012. № 16. pp. 31-46. DOI 10. 1007/s11043-011-9152.

7. Gnip I.Ya., Vaitkus S.I. (2013) Analytical description of mineral wool creeping deformation during prolonged compression // Building materials. 2013. 11. pp. 57-62

8. Zhukov A.D.,Smirnova T.V., Zelenshchikov D.B., KhimichA.O. (2014) Thermal treatment of the mineral wool mat // Advanced Materials Research (Switzerland) Vols. 838-841. pp. 196-200.

9. Rumyantsev, B.M., Zhukov, A.D., Zelenshikov, D.B., Chkunin, A.S., Ivanov, K.K., Sazonova, Yu.V. (2016). Insulation systems of the building constructions, in: MATEC Web of Conferences. Vol.86. DOI: 10.1051/matecconf/20168604027.

10. Bessonov I.V., Zhukov A.D., Bobrova E.Yu. (2015). Building systems and features of the use of thermal insulation materials. Magazine Housing Construction, no. 7, Moscow: OOO RIF, pp. 49-52. 
11. Zhukov A.D.Bobrova Ye.Yu., Zelenshchikov D.B., Mustafaev R.M., Khimich A.O. Insulation systems and green sustainable construction // Advanced Materials, Structures and Mechanical Engineering. Vols 1025-1026 (2014). pp. 1031-1034.

12. Hlevchuk V.R., Bezsonov I.V. On current thermal performance of mineral wool // Problems of construction of thermal physics, climate systems, and energy efficiency in buildings. Moscow, NIISF, 1998. pp. 127-135.

13. Rumiantcev B.M., Zhukov A.D., Bobrova E.Yu, Romanova I. P., Zelenshikov D.B., Smirnova T.V. The systems of insulation and a methodology for assessing the durability. / MATEC Web of Conferences. Vol. 86 (2016). DOI: http://dx.doi.org/10.1051/matecconf/ 20168604036.

14. Bobrov Yu.L. (1985) Express method and laboratory equipment for quality evaluation of porous materials // Abstracts of the report of the international scientificpractical conference "Modern methods of quality control problems and their solutions". 1985. pp. 43-44. 